\title{
EXPERIÊNCIAS DE ESTUDANTES DE ENFERMAGEM E PSICOLOGIA EM PESQUISA CLÍNICA COM PACIENTES COM HIV/AIDS E DOR CRÔNICA
}

\author{
Rafael Braz da Silva ${ }^{1}$, Gisele Keller da Rosa ${ }^{2}$, Jenifer Pereira Lopes ${ }^{2}$, \\ Rachel Nunes Lorenzoni², Andressa de Souza ${ }^{3}$
}

Resumo: Este estudo apresenta vivências de acadêmicos de Enfermagem e Psicologia em um projeto de iniciação científica, dentro de uma ONG situada em Porto Alegre/RS, especializada no atendimento de pacientes com HIV/AIDS. Os acadêmicos realizaram a produção de dados para uma pesquisa transversal que analisa a neurofisiologia da nocicepção e sensibilização central em indivíduos com neuropatia por HIV, na busca de melhor compreensão dos mecanismos fisiopatológicos envolvidos na dor e de sua correlação com a manifestação clínica em diferentes estágios da doença. Nesse contexto, o presente artigo pretende descrever experiências dos acadêmicos junto aos pacientes soropositivos, bem como o aprendizado proveniente das atividades realizadas. Nota-se a importância da inserção do aluno de iniciação científica em projetos de pesquisa, visando o treinamento de um profissional investigador, o contato com pacientes do estudo enriqueceu o saber e promoveu vivências em situações onde é preciso além de coletar dados saber escutar o indivíduo que muitas vezes está em situação de vulnerabilidade. Nesse contexto destacase a importância da organização de um estudo e na prática a responsabilidade e empatia no qual os pesquisadores (alunos e professores) abordam os participantes do estudo.

Palavras-chave: HIV. Dor Crônica. Entrevistas. Iniciação científica.

1 Acadêmico do curso de graduação em Psicologia e aluno de Iniciação Científica da linha de pesquisa na linha de pesquisa Desenvolvimento Humano e Processos Saúde-Doença. Centro Universitário Unilasalle, Canoas.

2 Acadêmico do curso de graduação em Enfermagem e aluno de Iniciação Científica da linha de pesquisa na linha de pesquisa Desenvolvimento Humano e Processos Saúde-Doença. Centro Universitário Unilasalle, Canoas.

3 Docente e pesquisador do Programa de Pós-Graduação em Saúde e Desenvolvimento Humano, linha de pesquisa Desenvolvimento Humano e Processos Saúde-Doença. Centro Universitário Unilasalle, Canoas. 


\title{
EXPERIENCES OF NURSING AND PSYCHOLOGY STUDENTS IN CLINICAL RESEARCH WITH HIV/AIDS PATIENTS AND CHRONIC PAIN
}

\begin{abstract}
This study presents experiences of Nursing and Psychology students in an undergraduate research project developed in a NGO dedicated to support HIV/AIDS patients of Porto Alegre city. The undergraduate students collected data for a cross-sectional research that studies the neurophysiology of nociception and central sensitization in patients with HIV neuropathy. The study investigates the pathophysiological mechanisms of pain and their correlation with the clinical manifestation in different stages of the disease. In this context, the present paper aims to describe how the students perceived the experience of sharing with HIV/AIDS patients, as well as the life lessons learnt while accomplishing their research activities. It is worth noting the relevance of including undergraduate students into research projects, as it trains future health professionals in areas beyond research methodology. The contact with patients within the study nurtured student knowledge and promoted situations that demanded active listening skills to collect data from subjects in vulnerability situation. In this context, we highlight the relevance of having researchers (professors and students) who are able to inspire responsibility and empathy in the studied population.
\end{abstract}

Keywords: HIV. Chronic Pain. Interviews. Undergraduate research.

\section{INTRODUÇÃO}

Desde a sua descoberta, no início da década de 1980, o Vírus da Imunodeficiência Humana (HIV) se apresenta como um dos maiores problemas de saúde de toda a história, sobretudo em razão do seu caráter pandêmico e de incríveis proporções econômicas e sociais (WAIDMAN; BESSA; SILVA, 2011). Inicialmente, acreditava-se que o HIV se restringia a "grupos de risco" (homens homossexuais, usuários de drogas injetáveis e prostitutas), com o passar dos anos, constatou-se a sua relação com a vulnerabilidade de cada indivíduo e seus aspectos sociais, culturais e econômicos (BRASIL, 2007; WAIDMAN; BESSA; SILVA, 2011). Nesse contexto, identifica-se, por exemplo, a maior suscetibilidade de mulheres à contaminação com o vírus, devido a suas reduzidas condições de negociação de práticas sexuais sem proteção com seus parceiros (BRASIL, 2007). Conforme Rodrigues et al. (2012), a vulnerabilidade feminina ao HIV está ligada ao modo como homens e mulheres se relacionam na sociedade brasileira, à dinâmica de poder que acompanha tais relações e às representações sociais sobre papéis de gênero, aspectos que, seguramente, constituem importantes variáveis na configuração do perfil da epidemia.

No Brasil, 734 mil pessoas vivem com HIV/AIDS, com maior prevalência na faixa etária entre 25 e 39 anos de idade, em ambos os sexos (BRASIL, 2014). Desde a década de 1980, medicamentos antirretrovirais (ARVs) têm sido empregados no tratamento contra a AIDS. Os primeiros permitiam benefícios temporários, em função da baixa eficácia na recuperação da capacidade imunológica e efeitos limitados sobre a redução da carga viral. De 1996 em diante, com o surgimento de novas classes de ARVs, foi possível atingir, com a terapia antirretroviral combinada, êxitos significativos 
no tratamento de pessoas infectadas pelo HIV. A partir de então, percebeu-se uma relevante redução nos índices de morbidade e mortalidade por AIDS (BONOLO; GOMES; GUIMARÃES, 2007; SEIDL et al., 2007). Entretanto, mesmo com a disponibilidade da terapia antirretroviral, verifica-se que alguns pacientes não têm usufruído das vantagens desse tratamento. Isso acontece por dificuldades na adesão, algo fundamental para o sucesso da terapêutica. Desse modo, a aquisição e a manutenção da conduta de adesão ao tratamento são aspectos imprescindíveis para a obtenção de bons resultados (SEIDL et al., 2007). Os efeitos máximos desejados do tratamento antirretroviral são alcançados quando se atinge, no mínimo, 95\% de adesão às doses prescritas (BONOLO; GOMES; GUIMARÃES, 2007; SEIDL et al., 2007). A complexidade da adesão aos ARV resulta das mudanças no cotidiano pelo uso diário dos medicamentos. Os efeitos colaterais (náuseas, enjoos, mal-estar) e as dificuldades de comunicação entre pacientes e profissionais da saúde são bastante relevantes na adesão ao tratamento (SEIDL et al., 2007).

Para além dos benefícios vinculados à terapia com ARVs, associa-se o uso desses medicamentos ao desenvolvimento de diferentes tipos de dor. A dor neuropática é uma delas (DE SOUZA et al., 2016) e afeta milhões de pessoas em todo o mundo (DWORKIN et al., 2007), embora ainda não se tenha dados precisos (FREYNHAGEN; BENNETT, 2009). Em sua maioria, os pacientes apresentam, dor crônica que, de modo prevalente, não cede à terapêutica e gera uma considerável queda na qualidade de vida (FREYNHAGEN; BENNETT, 2009). Devido ao grande número de causas subjacentes, há dificuldades em se quantificar a dor neuropática. No entanto, supõe-se que 6 a $8 \%$ da população mundial apresentem dor crônica de características neuropáticas (HAANPAA et al., 2009). Acredita-se que esses percentuais aumentem com o avanço da idade do indivíduo e da gravidade da doença base, e que a sua prevalência seja maior no sexo feminino (TORRANCE et al., 2006). Estima-se que 40 a $60 \%$ das pessoas soropositivas apresentam dor frequente, e que esta varie conforme o estágio da doença e o nível de adesão ao tratamento (DWORKIN et al., 2007).

No intuito de se produzir conhecimentos e de se estabelecer maiores correlações entre a soropositividade, o tratamento com antirretrovirais e a dor neuropática, foi realizada uma pesquisa transversal com sujeitos soropositivos que frequentam uma ONG especializada no contexto HIV/AIDs, situada no município de Porto Alegre/ RS. O desenvolvimento da referida pesquisa possibilitou a inserção de estudantes de Enfermagem e Psicologia em atividades de iniciação científica. Diante disso, o presente artigo tem o objetivo de descrever experiências desses acadêmicos durante a realização da pesquisa, desde a seleção dos participantes até a aplicação de testes e questionários às pessoas soropositivas. 


\section{RELATO DE EXPERIÊNCIA}

A pesquisa foi realizada dentro de uma ONG sem fins lucrativos especializada no contexto HIV/AIDS situada no município de Porto Alegre/RS. O local é mantido por uma organização religiosa e recebe doações de variados segmentos sociais. A instituição conta com a força de trabalho de alguns funcionários, estagiários e membros dessa ordem religiosa, e, majoritariamente, com o trabalho de algumas dezenas de voluntários que diariamente frequentam a ONG. Esse quadro de colaboradores atua com a finalidade de oferecer assistência e amparo a pessoas soropositivas. Cerca de 60 usuários são atendidos em cada tarde de trabalho. As atividades desenvolvidas são sempre planejadas e funcionam conforme o interesse dos sujeitos que frequentam o local. Nesse contexto, a confiança e os vínculos estabelecidos entre os usuários e quem os atende são fundamentais para o êxito das atividades realizadas. Em meio a esse cenário, ocorreram as atividades de iniciação científica relativas à pesquisa. $\mathrm{O}$ presente relato de experiência se refere às abordagens com pessoas soropositivas no período compreendido entre março de 2014 e novembro de 2015.

A produção de dados se iniciou com uma apresentação do grupo de trabalho, na qual foram passadas diversas informações sobre o projeto de pesquisa. Primeiramente, o público que frequenta a instituição foi orientado sobre o nível de segurança dos instrumentos de pesquisa que compõem o processo de produção de dados. Essas informações foram imprescindíveis para que houvesse transparência desde o início das abordagens, de modo a propiciar um clima de confiança capaz de eliminar - ou ao menos reduzir - o receio que algumas pessoas pudessem sentir em participar. $\mathrm{Na}$ oportunidade, destacou-se a importância da colaboração dos indivíduos que frequentam a $\mathrm{ONG}$, em razão do potencial impacto dos resultados do estudo frente às demandas de saúde e de qualidade de vida das pessoas no contexto HIV/AIDS.

Destaca-se que, a despeito da apresentação do projeto de pesquisa e das pessoas nele envolvidas, algumas semanas foram necessárias para que, aos poucos, os usuários do local fossem se ambientando com a presença dos acadêmicos na instituição. Vale ressaltar que o contexto HIV/AIDS é permeado por estigmas e preconceitos, um aspecto social que pode acrescer a desconfiança e o comportamento defensivo dos indivíduos ao se revelarem à pesquisa. Nesse sentido, tornou-se imprescindível que os acadêmicos apresentassem uma postura respeitosa e empática diante de pessoas marcadas por vivências de vulnerabilidade e sofrimento e que estavam dispostas a colaborar com o estudo.

O caráter comunitário e social da ONG faz com que, em sua expressiva maioria, a população que a frequenta seja formada por indivíduos que vivem em situações de vulnerabilidade social. Pessoas de baixa renda, ex-usuários de drogas, com baixa escolaridade, em situação de rua ou com moradia precária, dentre outras situações, compõem o público atendido. Assim, problemas de alfabetização, dificuldades cognitivas e aspectos psicológicos diversos, exigiram especial atenção e desenvoltura dos acadêmicos durante a produção de dados. 
Opta-se, no presente artigo, pelo uso da expressão "produção de dados" e não pela expressão mais usual "coleta de dados". Compreende-se que testes e questionários obtêm resultados que se referem, não somente ao sujeito, mas também ao momento e contexto vivenciados, bem como a outros fatores psicológicos e sociais que permeiam a sua vida. Com isso, entende-se que os dados são produzidos durante cada abordagem, ou seja, não são respostas prontas, guardadas pelos indivíduos e simplesmente "coletadas" junto aos mesmos durante a pesquisa.

Após a divulgação das informações ao grande grupo, iniciou-se a etapa de seleção de participantes e produção de dados. Assim, por meio da abordagem individual nos espaços de convivência da instituição, os sujeitos eram questionados sobre a sua disposição voluntária em fazer parte da pesquisa. As pessoas que concordavam, acompanhavam os acadêmicos até uma sala específica para a realização das atividades, para receber, ter ciência e assinar o Termo de Consentimento Livre e Esclarecido (TCLE) e então responder à entrevista inicial.

Ao se recrutar os sujeitos para participarem da pesquisa, além da sua vontade e disposição, fazia-se também necessário verificar - no momento de cada participação - a sua disponibilidade de tempo. Na instituição, voluntários das mais diversas áreas de atuação oferecem atendimentos ao longo de todas as tardes. Corte de cabelo, massagem, atendimento psicológico individual e grupal, dentre outros serviços e oficinas mantinham os indivíduos ocupados na maior parte do tempo. Raramente era possível aplicar sequencialmente os questionários e testes com a mesma pessoa, alternandose assim, as aplicações entre os participantes. Desse modo, evitava-se desperdício de tempo e "participações apressadas" de sujeitos que pudessem estar aguardando o início de alguma atividade com hora marcada.

No início de cada tarde, materiais e anotações eram revisados a fim de se verificar os potenciais participantes daquele dia e quais os instrumentos de pesquisa seriam utilizados para a melhor sequência do trabalho. Os primeiros questionamentos se referiam à inclusão / exclusão de indivíduos na pesquisa. Portadores de doenças crônicas, associadas à neuropatia, como diabetes, infecção por HTLV (Human T-cell Lymphotrophic Virus), dentre outras, eram automaticamente excluídos. Situações como ter feito uso de algum tipo de anti-inflamatório nos últimos sete dias e/ou haver a presença de doenças severas que limitassem a capacidade de compreensão dos questionamentos também se configuravam como fatores de exclusão.

Na sequência, era aplicada a Escala Análogo Visual, no intuito de quantificar a dor dos indivíduos. As Escalas de Catastrofismo (avaliação da magnificação, ruminação e desesperança), Escala de Depressão de Beck, Índice de Qualidade de Sono de Pittsburgh, Escala de Resiliência e a Escala IDATE (avaliação de níveis de ansiedade) eram aplicados com maior agilidade, por serem questionários de fácil entendimento e por solicitarem respostas simples, algumas delas dicotômicas. É importante destacar que antes da aplicação de cada questionário, os participantes eram devidamente informados sobre o seu método, conteúdo e objetivos. 
A aplicação da Escala SCID-II da Associação Americana de Psiquiatria quase sempre se mostrou extenuante. Trata-se de um questionário bastante extenso e invasivo, com indagações mais complexas do que as dos questionários anteriormente referidos. Assim, o grau de dificuldade de entendimento apresentado pelos sujeitos era mais significativo nessa etapa da aplicação de questionários. Além disso, o conteúdo do SCID-II aborda temas mais íntimos e delicados, que podem se apresentar como intimidadores aos entrevistados. Sobre esse aspecto, ressaltava-se que os questionamentos eram realizados da mesma forma para todos os participantes e que as perguntas não eram selecionadas conforme a sua história de vida ou o seu tipo de personalidade. Essa elucidação tinha o objetivo de evitar que os sujeitos saíssem da entrevista desconfiados e se perguntando, por exemplo, "por que será que fizeram tal pergunta para mim?”.

Durante o seu desenvolvimento, a pesquisa também produziu dados por meio de testes psicofísicos realizados com os participantes, também aplicados pelos acadêmicos. Cada teste era precedido por uma breve explicação sobre o seu método, funcionamento e objetivos, de forma que os participantes se sentissem seguros e confortáveis durante a sua realização. A sensibilidade cutânea era avaliada pelo teste de discriminação de dois pontos (DDP), realizado com um instrumento rígido de pontas arranjadas em pares em diferentes distâncias. Era um teste de rápida e simples aplicação, no qual os sujeitos respondiam se estavam sentindo uma ou duas pontas do instrumento deslizando por seus dedos. As exposições eram alternadas entre um e dois pontos, para se avaliar a capacidade de discriminação (sensibilidade cutânea).

Para confirmar ou descartar a presença de dor neuropática, realizava-se o teste LANSS (Leeds Assessment of Neuropathic Symptoms and Signs). Esse também consistia em um teste rápido e simples, mas que gerava um certo receio em algumas pessoas. O LANSS consiste em passar suavemente a ponta de uma agulha na pele, tanto na extremidade dolorosa, quanto na extremidade contrária, para se avaliar se o indivíduo percebe diferenças entre as passadas de agulha, nas referidas extremidades cutâneas. A prática desse teste era sempre precedida de orientações que indicassem a sua segurança e o fato de que não haveria quaisquer perfurações na pele com a agulha utilizada.

O mais extenso e complexo era o Teste Sensorial Quantitativo (QST), utilizado para medir limiares de dor e de temperatura, por meio da avaliação do grau de tolerância de cada pessoa. $\mathrm{Na}$ aplicação do QST, um termodo era posicionado no antebraço dominante do indivíduo e, gerenciado por software, tinha sua temperatura elevada até que o próprio testando sinalizasse o nível de dor ou calor percebido. O QST era aplicado em várias etapas, a fim de se medir a sensibilidade ao calor, a dor máxima tolerada e a dor de grau equivalente a $60 \%$ dessa dor máxima tolerada. Cada limiar era sinalizado pelo testando por meio de um dispositivo semelhante a uma caneta, posicionado em sua mão não dominante. Exceto a medição da dor máxima tolerada, todas as medições do QST eram efetuadas por três vezes, em razão do resultado ser analisado - posteriormente - pela média dos valores medidos. 
$\mathrm{Na}$ sequência do QST e, em conjunto com ele, realizava-se sempre o teste de Modulação da Dor condicionada (CPM, do inglês Conditional Pain Modulation). Desse modo, simultaneamente à produção de calor pelo termodo posicionado no antebraço dominante, um estímulo doloroso era produzido na mão não dominante por sua imersão em água com gelo (temperaturas entre zero e $1,5^{\circ} \mathrm{C}$ ), durante um minuto. $\mathrm{O} C P M$ era realizado por três vezes a fim de se obter dados suficientes sobre sensibilidade, relação entre as duas diferentes fontes de dor, tolerância, intensidade percebida, etc.

No princípio das atividades, acreditava-se ser possível aplicar toda a sequência de questionários e testes com o mesmo participante em uma só abordagem. Com o passar das semanas e a consequente aquisição de experiência, percebeu-se o quanto essa metodologia era extenuante para todos os envolvidos. Assim, cada sujeito passou a ser requisitado por cerca de três vezes ao longo de toda a etapa de produção de dados. Dessa forma, geralmente, o participante respondia a todos os questionários mais breves na primeira abordagem, ao SCID-II na segunda e, finalmente, realizava os testes na terceira e última abordagem. Houve, contudo, situações nas quais os indivíduos foram requisitados mais vezes, seja por questões de tempo ou de indisponibilidade de materiais em ocasiões específicas. Os acadêmicos mantinham disponíveis balas e pirulitos que eram oferecidos aos indivíduos no final de cada abordagem, como um agradecimento simbólico por sua vontade e disponibilidade em contribuir com o projeto.

Conforme o funcionamento da instituição, as atividades eram sempre realizadas no turno da tarde, com a presença de dois ou três acadêmicos em cada dia. Os questionários eram aplicados por um ou dois acadêmicos e os testes eram sempre aplicados por uma dupla de trabalho. A pesquisa teve seu foco em sujeitos do sexo feminino, com mais de 50 mulheres participantes. Isso porque o maior número de usuários da instituição pertence a este gênero. Não obstante, cerca de 10 homens também participaram da pesquisa, o que possibilitou a diversificação da experiência dos acadêmicos.

Trabalhar com naturalidade e de forma compreensiva foi algo que contribuiu significativamente para o êxito das abordagens, de modo que os sujeitos pudessem relaxar durante a sua participação na pesquisa. A aplicação de questionários e testes, por vezes, gerava dúvidas nos participantes. Assim, os acadêmicos precisavam, com atenção, seguir o procedimento de repetir a orientação e/ou a leitura aos sujeitos, de modo a propiciar a compreensão dos questionamentos. Houve vezes em que a simples repetição não foi suficiente para sanar dúvidas e, diante disso, os entrevistadores tinham o desafio de facilitar o entendimento, com bastante cuidado, para não distorcer questões e não influenciar nas respostas dos participantes.

O SCID-II foi sempre o questionário mais intenso no que diz respeito a recordações de experiências. Nele, temas como adolescência, uso de drogas, violência, suicídio, dentre outros eram abordados. O questionário tem potencial para evocar lembranças indesejadas e vivências de sofrimento, inclusive de épocas remotas da vida de cada um, fatos e situações que há muito não eram recordados. Durante sua aplicação, os sujeitos ficavam suscetíveis a rememorar vivências incômodas, negativas, traumáticas, etc. 
Além de ser invasivo, o SCID-II é extenso e, assim, tornava-se bastante cansativo aos participantes. Com isso, os acadêmicos precisavam se manter especialmente atentos às reações dos entrevistados, a fim de se identificar se estes demonstravam alguma mudança de humor, tristeza ou qualquer desconforto em responder às questões, avaliando a necessidade de pausas e demonstrando uma postura acolhedora aos entrevistados.

Não somente o SCID-II, mas também os demais questionários utilizados na pesquisa, propiciavam aos entrevistados a recordação de momentos difíceis e/ou ruins de suas vidas. Essa dinâmica, por vezes, mobilizava ansiedades nos indivíduos, que, demonstravam a necessidade de conversar e de expor seus sentimentos. Quando isso ocorria, as respostas não eram dadas de forma curta e objetiva, mas carregadas de vivências e histórias pessoais detalhadas. Diante disso, os acadêmicos tinham de manter o foco objetivo na pesquisa, conduzindo os entrevistados a responderem às questões e, ao mesmo tempo, darem atenção, sendo minimamente continentes das ansiedades provocadas nos sujeitos, sem demonstrarem qualquer frieza ou desinteresse por suas narrativas.

O interesse e a disposição dos acadêmicos sempre serviram como agentes facilitadores na criação de vínculos com os entrevistados. O respeito e a qualidade das relações estabelecidas foram critérios básicos para o bom andamento das atividades, o que possibilitou a mútua confiança no decorrer da pesquisa. Os acadêmicos prestavam esclarecimentos e informações aos participantes que, desse modo, obtinham condições de fornecer respostas confiáveis durante a produção de dados. Os acadêmicos também permaneciam atentos à disposição dos entrevistados, em razão do cansaço ser um fator que poderia influenciar e distorcer as respostas fornecidas. Respostas apressadas e/ ou repetitivas, por exemplo, eram sinais de que a participação do indivíduo deveria ser retomada em outra oportunidade, a fim de se minimizar as margens de erro da pesquisa.

A exceção do QST, que sua aplicação era bastante simples e rápida. Por ser um teste realizado em várias etapas e por demandar uma compreensão mais complexa, exigia que os acadêmicos explicassem cada passo da testagem, com orientações sobre a necessidade do sujeito sinalizar os limites de dor e temperatura tolerados. Fazia-se também, a distinção entre cada uma de suas etapas: limiar de calor, limiar de dor e grau de dor. Ao longo da pesquisa, a experiência fez com que a aplicação do QST transcorresse de forma cada vez mais tranquila e eficaz, sem a necessidade de se refazer medidas.

Os participantes da pesquisa, por vezes, perguntavam quais cursos os acadêmicos faziam. Ao tomarem conhecimento de que eram estudantes de Enfermagem e de Psicologia, em geral, falavam sobre seus sentimentos e experiências, demonstrando uma necessidade de receberem atenção e de serem escutados. A população que frequenta a instituição é atendida pelo Sistema Único de Saúde (SUS), muitas vezes, em consultas que têm pouco tempo de duração. A despeito disso, durante as atividades de pesquisa, quando questionavam especificamente sobre a sua saúde e sobre a soropositividade, 
os sujeitos eram orientados a direcionar seus questionamentos aos profissionais de saúde que os acompanhavam, em razão dos acadêmicos não possuírem condições de atenderem a essa demanda.

No final de sua participação, algumas pessoas perguntavam "como haviam se saído" nos questionários e testes. Nesses casos, recebiam informações sobre a importância dos dados obtidos por meio de sua colaboração para os futuros resultados do estudo e que os instrumentos utilizados não lhes avaliavam imediata e isoladamente. Em tais oportunidades, por vezes, questionavam sobre o término do estudo e sobre a divulgação dos resultados. Com isso, eram esclarecidas sobre as etapas da pesquisa e informadas que, após a conclusão do estudo, serão distribuídos materiais de divulgação e realizadas palestras às pessoas que frequentam a instituição. Destaca-se, por fim, que as atividades e rotinas supra descritas foram desenvolvidas e ajustadas continuamente ao longo de quase dois anos dentro da instituição, com muito aprendizado sobre produção de dados para pesquisa e sobre o contexto da população soropositiva.

\section{CONSIDERAÇÕES FINAIS}

A realização de uma pesquisa exige postura ética e respeitosa de quem a desenvolve. No trabalho em questão, fez-se necessário considerar que os sujeitos participantes estavam na instituição por motivações diversas, alheias ao estudo. Tal consideração serviu como ponto de partida dos acadêmicos ao entrarem em contato com cada pessoa a ser recrutada. Nesse sentido, os participantes foram sempre informados sobre a importância da sua colaboração, na medida em que se pretende obter resultados que produzam benefícios à saúde integral da população soropositiva, incluindo, portanto, a sua própria saúde.

As atividades de produção de dados buscaram interferir minimamente nas rotinas dos indivíduos e da instituição. Entretanto, conclui-se que não existe intervenção sem interferência, ou seja, cada seleção, cada entrevista, cada troca de experiências e cada vínculo formado promove transformações em todas as pessoas envolvidas. Com isso, foi imprescindível que as abordagens fossem realizadas com muita responsabilidade e empatia. Ao final dessa etapa, constata-se que, para além da aquisição do conhecimento técnico em pesquisa, as experiências vividas propiciaram aos acadêmicos um grande aprendizado sobre as relações humanas no contexto da saúde, no qual os profissionais devem conhecer bem o seu papel frente àqueles que lhes confiam a sua história de vida.

FOMENTO: Universal CNPQ (processo 442479/2014-0, Andressa de Souza) e Centro Universitário La Salle, Canoas.

\section{REFERÊNCIAS}

BONOLO, P. F.; GOMES, R. R. F. M.; GUIMARÃES, M. D. C. Adesão à terapia antiretroviral (HIV/AIDS): fatores associados e medidas da adesão. Epidemiologia e 
Serviços de Saúde, Brasília, v. 16, n. 4, p. 261-278, out./dez., 2007. Disponível em: <http:// scielo.iec.pa.gov.br/pdf/ess/v16n4/v16n4a05.pdf>. Acesso em: 20 nov. 2015.

BRASIL. Ministério da Saúde. Secretaria de Vigilância em Saúde. Boletim Epidemiológico - Aids e DST. Brasília: Ministério da Saúde, 2014. Disponível em: <http://www.aids.gov. br/sites/default/files/anexos/publicacao/2014/56677/boletim_2014_final_pdf_15565.pdf>. Acesso em: 10 out. 2015.

BRASIL. Ministério da Saúde. Secretaria de Vigilância em Saúde. Plano Integrado de Enfrentamento da Feminização da Epidemia de Aids e outras DST. Brasília: Ministério da Saúde, 2007. Disponível em: <http://bvsms.saude.gov.br/bvs/publicacoes/plano_feminizacao_ final.pdf>. Acesso em: 10 out. 2015.

DE SOUZA, A. et al. Dor neuropática em pacientes com HIV/AIDS em uso de terapia antirretroviral. Clinical \& Biomedical Research, Porto Alegre, v. 36, n. 3, p. 156-164, out., 2016. Disponível em: <http://www.seer.ufrgs.br/index.php/hcpa/article/view/65984>. Acesso em: 18 dez. 2016.

DWORKIN, R. H. et al. Pharmacologic management of neuropathic pain: evidence-based recommendations. Pain, v. 132, n. 3, p. 237-251, dez., 2007. Disponível em: <http://www. ncbi.nlm.nih.gov/pubmed/17920770>. Acesso em: 24 ago. 2015.

FREYNHAGEN, R.; BENNETT, M. I. Diagnosis and management of neuropathic pain. BMJ, v. 339, 2009. Disponível em: <http://www.bmj.com/content/339/bmj.b3002>. Acesso em: 24 ago. 2015.

HAANPAA, M. L. et al. Assessment of neuropathic pain in primary care. The American Journal of Medicine, v. 122, p. 13-21, 2009. Disponível em: <http://www.ncbi.nlm.nih.gov/ pubmed/19801048>. Acesso em: 17 set. 2015.

RODRIGUES, L. S. A. et al. Vulnerabilidade de mulheres em união heterossexual estável à infecção pelo HIV/Aids: estudo de representações sociais. Revista da Escola de Enfermagem da USP, São Paulo, v. 46, n. 2, p. 349-355, abr., 2012. Disponível em: <http://www.scielo.br/ pdf/reeusp/v46n2/a12v46n2.pdf>. Acesso em: 17 dez. 2016.

SEIDL, E. M. F.; MELCHÍADES, A.; FARIAS, V.; BRITO, A. Pessoas vivendo com HIV/AIDS: variáveis associadas à adesão ao tratamento antiretroviral. Cadernos de Saúde Pública, Rio de Janeiro, v. 23, n. 10, p. 2305-2316, out., 2007. Disponível em: <http://www. scielosp.org/pdf/csp/v23n10/06.pdf>. Acesso em: 20 nov. 2015.

TORRANCE, N. et al. The Epidemiology of Chronic Pain of Predominantly Neuropathic Origin. Results From a General Population Survey. The Journal of Pain, v. 7, n. 4, p. 281289, 2006. Disponível em: <http://www.jpain.org/article/S1526-5900(05)01029-1/pdf>. Acesso em: 24 ago. 2015.

WAIDMAN, M. A. P.; BESSA, J. B.; SILVA, F. L. C. Viver com AIDS e sofrer psiquicamente. Revista da Rede de Enfermagem do Nordeste, Fortaleza, v. 12, n. 1, p. 173180, jan./mar., 2011. Disponível em: <http://www.revistarene.ufc.br/vol12n1_pdf/a23v12n1. pdf>. Acesso em: 20 nov. 2015. 